\title{
Immunoelectron Microscopic Localization of HLA-DR Antigen in Control Small Intestine and Colon and in Inflammatory Bowel Disease
}

\author{
ICHIRO HIRATA, MD, LINDA L. AUSTIN, BA, WALTER H. BLACKWELL, BA, \\ JOHN R. WEBER, BS, and WILLIAM O. DOBBINS III, MD
}

\begin{abstract}
We have elucidated the distribution of 12 (HLA-DR) antigen in control and inflammatory bowel disease specimens, using immunoelectron microscopic methods. Control small intestinal epithelium and inflammatory bowel disease epithelium expressed 12 antigen, while control colonic epithelium did not. $I 2$ expression by enterocytes was more frequent on the lateral and basal surface than on the microvillus surface. Two of three $M$ cells in control ileum expressed 12 antigen. I2-positive intraepithelial lymphocytes were rarely detected in both control and disease specimens. 12-positive lamina propria lymphocytes were significantly increased in inflammatory bowel disease, while I2-positive lamina propria lymphocytes were virtually absent in control specimens. 12-positive mononuclear cells in the intestinal lamina propria were largely macrophages and monocytes in both control and inflammatory bowel disease specimens. I2-positive mononuclear cells resembling dendritic cells were not detected in control or disease specimens. Furthermore, there were no significant morphological differences in I2-positive or -negative macrophages and monocytes in control and disease specimens. The expression of 12 antigen on Schwann cells was detected more frequently in disease specimens than in control specimens. Capillary endothelia of both control and disease specimens expressed $I 2$ antigen. We demonstrate that 12 expression is present on surface membranes of both immune and nonimmune cells of the intestine and colon and show that this expression is more prominent in inflammatory bowel disease than in control intestine and colon. Further studies are required to determine whether this finding is meaningful in terms of antigen presentation and whether this apparent "immune activation" is involved in the pathogenesis of inflammatory bowel disease.
\end{abstract}

The pathogenesis of inflammatory bowel disease (IBD) is still unknown. The possibility that there may be a defect of local immune function in IBD

\footnotetext{
Manuscript received August 22, 1985; revised manuscript received November 7, 1985; accepted January 27, 1985.

From the Departments of Internal Medicine, University of Michigan Medical School and Veterans Administration Medical Center, Ann Arbor, Michigan.

Supported by funding from the National Foundation for Ileitis and Colitis and by Merit Review funds from the Veterans Administration.

Dr. Hirata's current address is: The 2nd Division of Internal Medicine, Osaka Medical College, 2-7 Daigaku-machi, Takatsuki Osaka, Japan.

Address for reprint requests: Dr. William O. Dobbins III, Veterans Administration Medical Center, 2215 Fuller Road, Ann Arbor, Michigan 48105.
}

has been the subject of several recent studies. These experimental approaches are mainly divided into two categories (1-14). One involves the evaluation of mononuclear cells (MNC) isolated from gut mucosa (1, 3-10). The other approach involves an enumeration of MNC subset in situ in mucosal tissue sections $(2,3,11-14)$. Some reports have suggested the presence of an immunoregulatory disturbance in IBD $(4-6,8)$, while others have found no evidence of such a disturbance in IBD $(1-3,7,9,10)$.

In order to further elucidate the mucosal immune status in IBD, it seems important to observe not only mucosal MNC function and phenotypic expression but also to examine mucosal immune 
activation as manifested by expression of class II major histocompatibility complex (MHC) antigens. HLA-DR (human leukocyte antigen, D-related locus) antigen, one of the class II MHC antigens, plays an essential role in the activation of the immune response in terms of antigen presentation $(15,16)$. There are several light microscopic reports of HLA-DR antigen distribution in mucosal tissue sections $(2,11-14,17-20)$, while there are no electron microscopic studies in this regard. In the present study, using immunoperoxidase staining, we have examined HLA-DR antigen distribution in the intestinal and colonic mucosa of controls and of patients with IBD. Our data extend the earlier light microscopic observations (2,11-14, 17-20), and we report additional observations that may provide insights into the immune response in the intestine and in IBD.

\section{MATERIALS AND METHODS}

Source of Tissue. Specimens of intestinal tissue were obtained from surgical and endoscopic procedures performed for diagnostic and therapeutic purposes at the University of Michigan affiliated hospitals. The specimens used for control purposes were obtained from grossly and histologically normal margins of five small intestinal (two colon cancer, one diverticulitis, one pseudocyst of the pancreas, one ileal stricture due to testicular tumor metastasis) and five colonic specimens (three colon cancer, one colon polyp, one diverticulitis) obtained from patients without inflammatory bowel disease. The IBD specimens were obtained from five patients with Crohn's ileitis (all surgical resections) and five patients with ulcerative colitis (two surgical resections, three endoscopic procedures). All IBD specimens showed characteristic features of disease grossly and microscopically. None of the grossly normal margins of IBD specimens were used to define control values. All IBD specimens showed histologically active changes. The studies described were approved in advance by the Human Studies Committee at the respective hospitals.

Patient Treatment (within 6 weeks before tissue procurement). Of the five patients with Crohn's disease, two were receiving both corticosteroids and sulfasalazine (Azulfidine, Pharmacia, Inc.), two were receiving Flagyl alone, and one was receiving no treatment at the time the tissue specimens were obtained. Of the five patients with ulcerative colitis, one was receiving corticosteroids alone, two were receiving sulfasalazine alone, one was receiving both corticosteroids and sulfasalazine, and one was receiving no treatment at the time the tissue specimens were obtained.

Monoclonal Antibodies. The monoclonal antibody to HLA-DR antigen was obtained from Coulter Immunology (a division of Coulter Corporation, Hialeah, Florida). The specificity of this monoclonal antibody, called I2 monoclonal antibody, is as follows: I2 monoclonal antibody reacts with an HLA-D/DR-related Ia-like antigen found on the cell surface membranes of normal B cells, monocytes, and activated $\mathrm{T}$ lymphocytes from all heterozygous individuals tested but does not react with some homozygous typing cells which express DR 7 or DR 11 (21). The dilution found to be optimal for electron microscopic localization of I2 monoclonal antibody was 1 to 640 . The above concentration was obtained by diluting the stock solution in $2 \%$ fetal calf serum (FCS) in $0.045 \mathrm{M}$ phosphate-buffered saline (PBS), $\mathrm{pH} 7.2$, with $0.002 \%$ merthiolate used as preservative. Staining controls consisted of staining of sections in the absence of primary antibody and staining of sections with irrelevant monoclonal antibody, namely anti-T4, helper $\mathrm{T}$ cell marker (1 to 20, Coulter clone), and anti-T8 antibody, suppressor/cytotoxic $\mathrm{T}$ cell marker (1 to 20, Coulter clone), instead of 12 antibody.

Immunoelectron Microscopic Peroxidase Procedure. Tissue specimens were stained according to modifications of Cerf-Bensussan et al (11). In brief, pieces of the tissue specimens $(1 \times 2 \times 4 \mathrm{~mm})$ were fixed in Nakane's fixative (22) containing $2 \%$ paraformaldehyde, $0.75 \mathrm{M}$ lysine, and $0.01 \mathrm{M}$ sodium periodate in $0.0375 \mathrm{M}$ phosphate buffer,

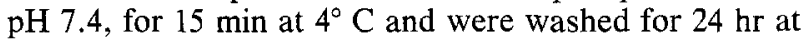

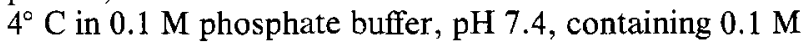
sucrose. Then the tissue was embedded in $5 \%$ agar (Difco, Detroit, Michigan) and sections $125-150 \mu \mathrm{m}$ thick were cut with a Sorvall TC-2 tissue sectioner (Sorvall Inc., Norwalk, Connecticut). Sections from each biopsy were incubated with 12 monoclonal antibody, with irrelevant monoclonal antibody (anti-T4 and T8), and with PBS for $24 \mathrm{hr}$. This was followed by incubation with a 1 to 100 dilution $(15 \mu \mathrm{g} / \mathrm{ml})$ of biotinylated horse anti-mouse IgG (Vector Labs, Burlingame, California) in $2 \%$ FCS in PBS for $2 \mathrm{hr}$. The section was then incubated with avidin-horseradish peroxidase (HRP) (Vector Labs) at final concentration of $25 \mu \mathrm{g} / \mathrm{ml}$ diluted in $2 \%$ FCS in PBS for $2 \mathrm{hr}$. All incubations were performed at room temperature in a microculture plate (3040 Microtest II tissue culture plate, Falcon Plastics, Oxnard, California) on a rotary table in a moist chamber. Each incubation was followed by three 15-min PBS, $\mathrm{pH} 7.2$, washes.

After avidin-HRP incubation the section was fixed with $2 \%$ glutaraldehyde- $0.1 \mathrm{M}$ sucrose- $0.004 \mathrm{M} \mathrm{CaCl}_{2}$ in 0.075 $\mathrm{M}$ sodium cacodylate, $\mathrm{pH} 7.3$, for $30 \mathrm{~min}$ at room temperature. Then the section was preincubated in $0.05 \%$ diaminobenzidine (Sigma Chemical Co., St. Louis, Missouri) in PBS, pH 7.2, for 30 min, followed by incubation in the same solution with $0.03 \%$ hydrogen peroxide for 30 $\mathrm{min}$ at room temperature. After washing in PBS overnight, the sections were postfixed in $1 \%$ osmium-1.5\% potassium ferrocyanide in water for $1 \mathrm{hr}$ at room temperature, dehydrated in graded ethanol solutions, and embedded in Epon using Beem plastic capsules (Ernest F. Fullam, Inc., Schenectady, New York). Then the section embedded in Epon was incubated at $60^{\circ} \mathrm{C}$, overnight or longer. Sections $1 \mu \mathrm{m}$ thick and ultrathin sections were cut on a Porter-Blum ultramicrotome (Ivan Sorvall Inc., Norwalk, Connecticut). Sections (1 $\mu \mathrm{m}$ thick) were stained with toluidine blue for light microscopic examination, and then the blocks were trimmed for ultrathin sections. Ultrathin sections were examined both 
unstained or stained with uranyl magnesium acetate and with lead citrate, and the sections were examined with an Hitachi (HU-llC-1) electron microscope.

Observations and Quantitative Analysis. All tissue sections were first observed and selectively photographed at various magnifications in order to determine the localization of I2 antigen in various cells. Sections were then scanned at low magnification (about $\times 2600$ ), and all areas of the lamina propria containing lymphocytes, monocytes, and macrophages, whether stained or unstained with 12 , were photographed. Four specimens from each of the four groups were examined quantitatively. Then all mononuclear cells were counted and recorded as stained or unstained with $\mathrm{I} 2$. The specific reaction of the monoclonal antibody with the $\mathrm{I} 2$ antigen was defined as the presence of a high-electron-density material on cell surface membranes. Intracellular I 2 was not clearly detected. Most observations were made on sections that had been counterstained with heavy metals. Specificity of staining was repeatedly confirmed using unstained sections obtained immediately adjacent to the stained sections.

Statistical Analysis. The Student's $t$ test was used for all calculations.

\section{RESULTS}

I2 Artigen Localization: Control Observations. In the epithelial layer, epithelial cells weakly stained with $\mathbf{I} 2$ on apical and basolateral cell surface membrane were detected in $3 / 5$ small intestinal specimens (Figure 1). Epithelial surface membrane staining by $\mathrm{I} 2$ was not detected in the five colonic specimens (Table 1). Three $M$ cells were fortuitously observed in $2 / 5$ small intestinal (ileal) specimens, and two of these expressed $\mathrm{I} 2$ on their apical surface membrane (Figure 2) and weakly expressed I2 on their lateral surfaces. High-electron-density small vesicles were occasionally seen on the apical side of epithelial cell cytoplasm. These vesicles were observed not only in sections stained with $\mathrm{I} 2$ monoclonal antibody but also in control sections, ie, sections stained without primary antibody and in sections stained with irrelevant monoclonal antibody (anti-T4 and T8). Therefore, we could not be certain that these high-electron-density small vesicles contained I2. Neither I2-positive endocrine cells nor 12-positive Paneth cells were detected in control specimens. Of the intraepithelial lymphocytes (IEL) coincidentally detected in the scanning photographs, two of eight IEL detected in five colonic specimens were I 2 positive and none of ten IEL detected in five small intestinal specimens were I2 positive (Table 1).

In the lamina propria, the I2-positive mononuclear cells were predominantly macrophages which

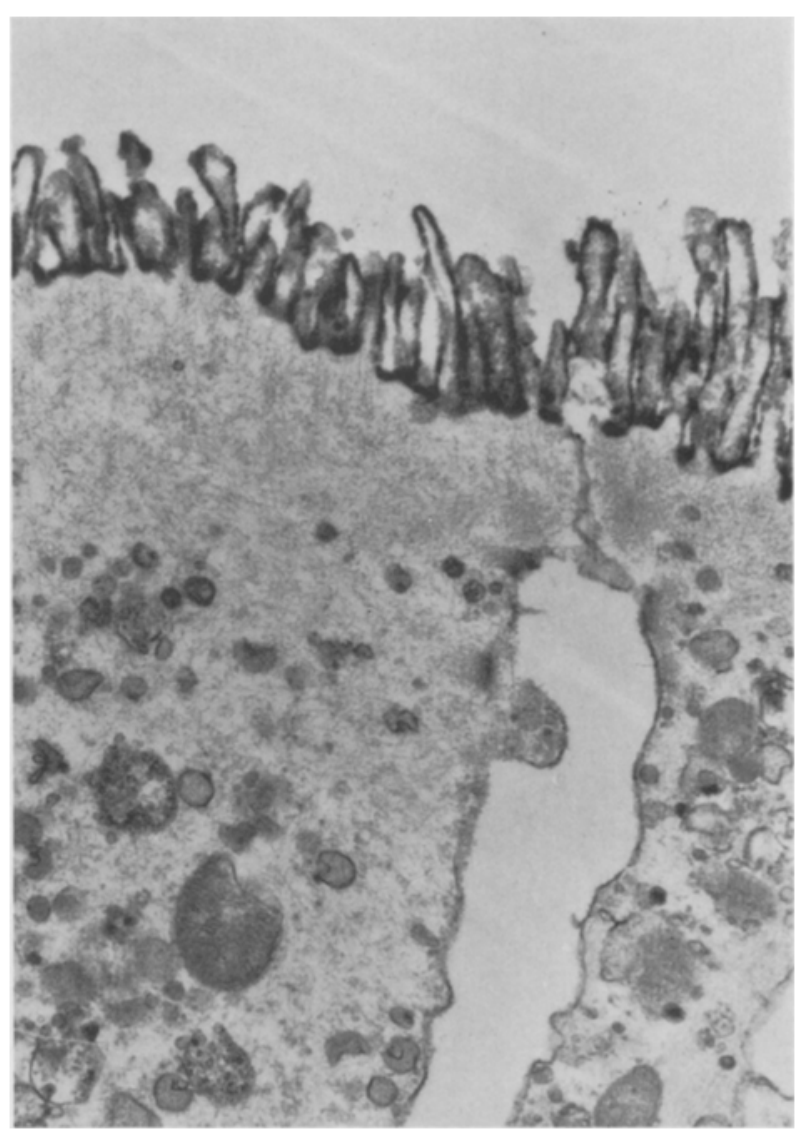

Fig 1. Electron micrograph of control small intestinal epithelium stained with I2 monoclonal antibody. Microvilli are stained (irregular dark precipitate on surface of microvilli), but there is no staining of lateral plasma membranes in this figure. $\times 21,700$.

were characterized by the presence of an oval or slightly lobulated nucleus, little heterochromatin, very abundant cytoplasm, numerous mitochondria, many vesicles, ample rough endoplasmic reticulum, well-developed Golgi area, many lysosomes, surface ruffles, and some phagolysosomes (Figure 3). Other I2-positive mononuclear cells were monocytes which were characterized by a lobulated or kidney shaped nucleus, thick rim of heterochromatin, small amount of cytoplasm, some rough endoplasmic reticulum, some mitochondria, many vesicles, few ruffles, and absence of phagolysosomes (Figure 4). 12 positive lamina propria lymphocytes (LPL) were unusual. More details about these mononuclear cells is given later. Five I2-positive fibroblasts (32 fibroblasts observed) were detected in $3 / 5$ colonic specimens. No 12 positive fibroblasts (21 fibroblasts observed) were detected in the five small intestinal specimens (Table 1). There was one I2-positive Schwann cell in 21 
HIRATA ET AL

Table 1. Qualitative Distribution of $12 *$

\begin{tabular}{lccccccc}
\hline & $\begin{array}{c}\text { Epithelial } \\
\text { cells }\end{array}$ & IEL & $\begin{array}{c}\text { Macrophage- } \\
\text { monocytes }\end{array}$ & LPL & Fibroblasts & $\begin{array}{c}\text { Schwann } \\
\text { cells }\end{array}$ & $\begin{array}{c}\text { Endothelial } \\
\text { cells }\end{array}$ \\
\hline Control small bowel & $3 / 5$ & $0 / 5$ & $5 / 5$ & $0 / 5$ & $0 / 5$ & $0 / 5$ & $5 / 5$ \\
Control colon & $0 / 5$ & $1 / 5$ & $5 / 5$ & $1 / 5$ & $3 / 5$ & $1 / 5$ & $5 / 5$ \\
Crohn's ileitis & $5 / 5$ & $1 / 5$ & $5 / 5$ & $4 / 5$ & $0 / 5$ & $3 / 5$ & $2 / 4$ \\
Ulcerative colitis & $5 / 5$ & $0 / 5$ & $4 / 4$ & $4 / 4$ & $1 / 4$ & $4 / 4$ \\
\hline
\end{tabular}

*The number of specimens containing I2-stained cells is found in the numerator and the total number of specimens examined in the denominator. IEL, intraepithelial lymphocyte; LPL, lamina propria lymphocyte.

cells detected in $1 / 5$ colonic specimens (Table 1 ). I2-positive capillary endothelia were easily detected in all small intestinal and colonic specimens (Figure 5 , Table 1). Lymphatic endothelium was detected in one small intestinal specimen only, and it was I2 positive.

I2 Antigen Localization: IBD Observations. Only the epithelial layer was examined in one of five ulcerative colitis specimens because the lamina propria was damaged by the endoscopic procedure. All Crohn's ileitis specimens (5/5) and all ulcerative colitis specimens (5/5) showed presence of I2-positive epithelial cells (Figure 6A, B, Table 1). Even so, 12 staining was patchy in distribution and varied in intensity among the specimens. Furthermore, lateral and basal surface 12 antigen expression by enterocytes was more frequent than microvillus $\mathrm{I} 2$ expression (Figure 7). One of four IEL in five Crohn's ileitis specimens was I2 positive, and all three IEL detected in the 5 ulcerative colitis specimens were I2 negative (Table 1).

In the lamina propria, I2 stained mononuclear cells were predominantly macrophages and were less often monocytes and lymphocytes (Figure 8). I2-positive fibroblasts were rarely detected $(1 / 25)$ in ulcerative colitis and were not detected $(0 / 20)$ in the Crohn's ileitis specimens (Table 1). I2-positive Schwann cells were sometimes detected in Crohn's ileitis (6/12 cells) and in ulcerative colitis ( $4 / 4$ cells) (Figure 9) (Table 1). I2-positive capillary endothelia were easily detected in $4 / 5$ Crohn's ileitis and $4 / 4$ ulcerative colitis specimens (Table 1).

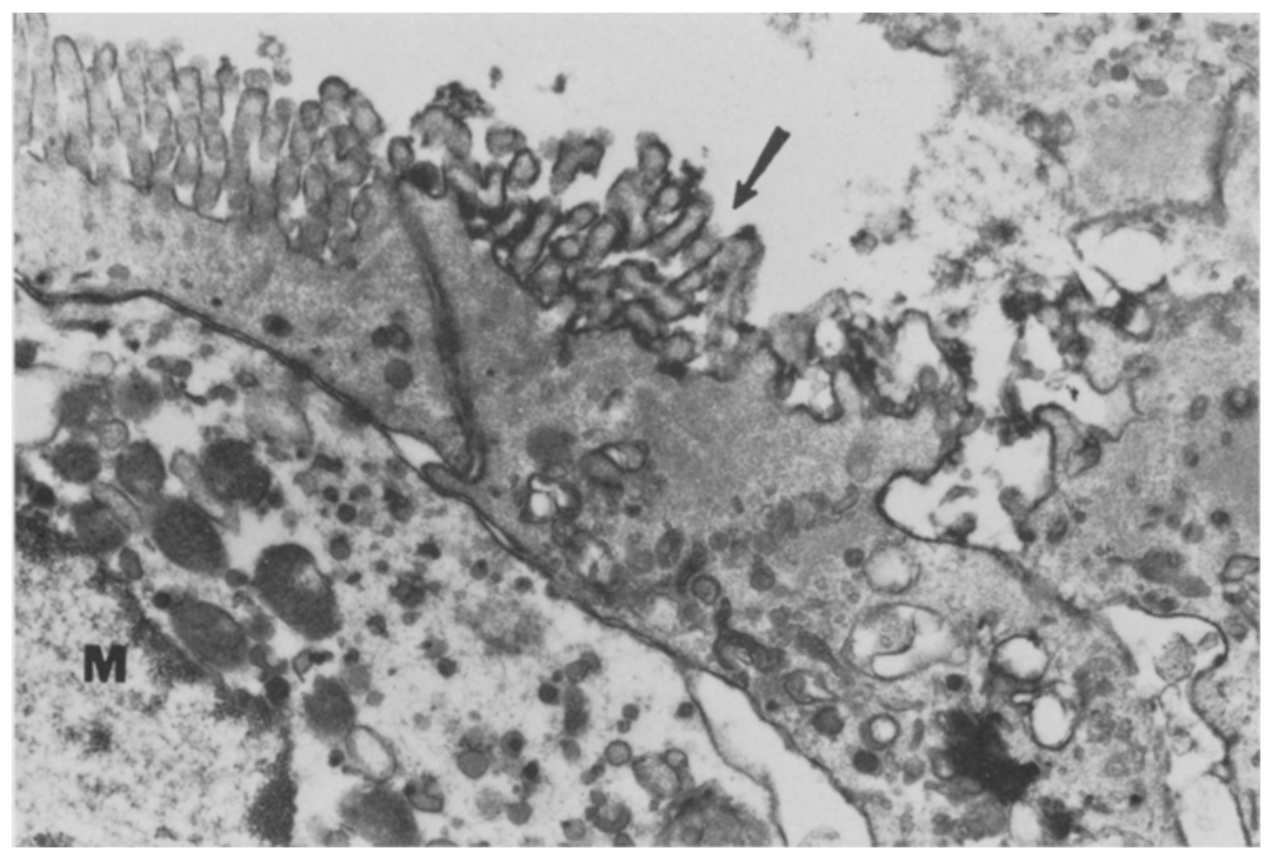

Fig 2. Electron micrograph showing presence of two adjacent $M$ cells in control ileum, one of which is stained with $\mathbf{2}$ monoclonal antibody. Microvilli (arrow) and lateral surface of the $\mathrm{M}$ cell are faintly stained. The mononuclear cell $(\mathrm{M})$ is enveloped by the $\mathrm{M}$ cells. $\times 18,800$. 


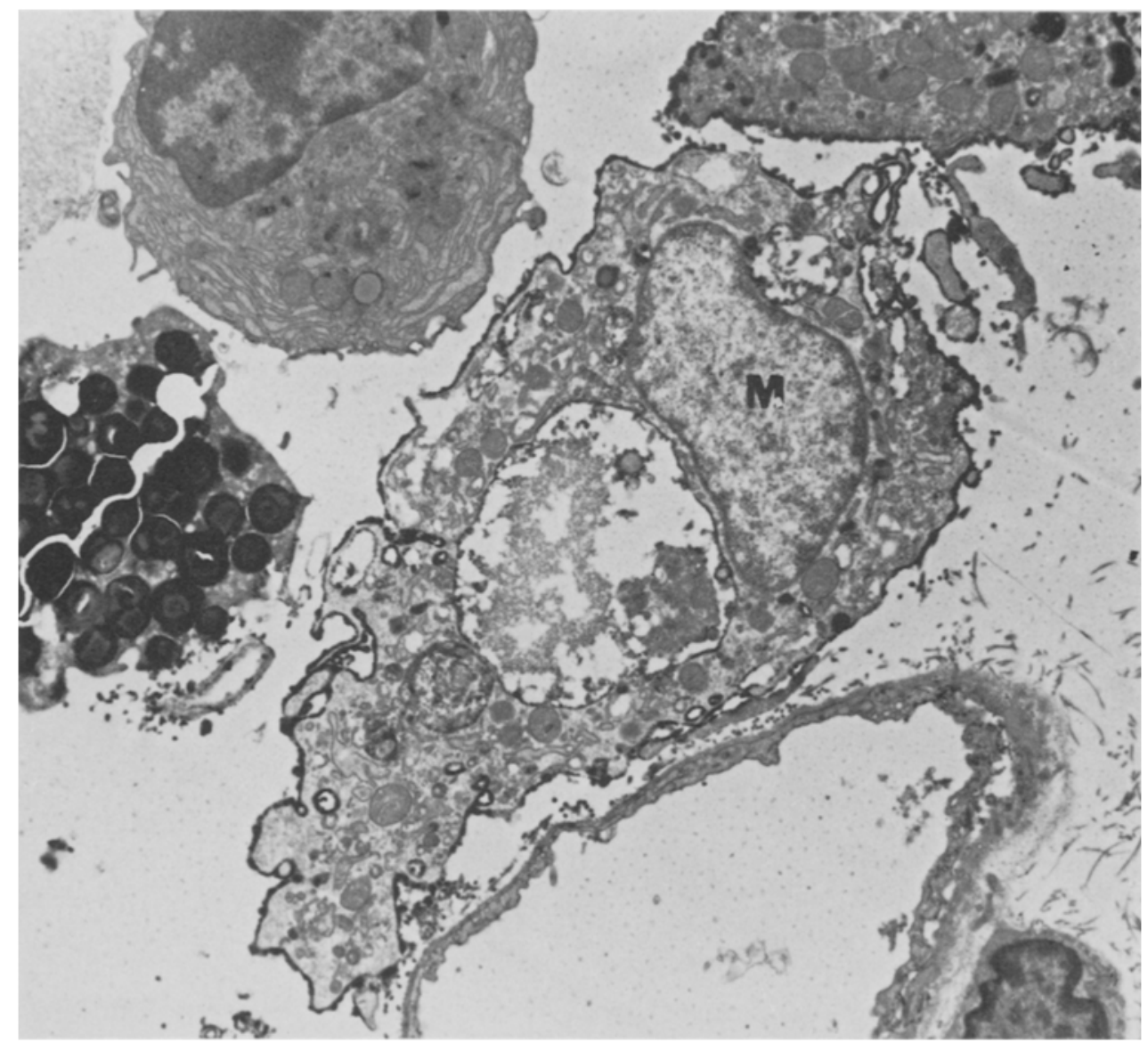

Fig 3. Electron micrograph of a macrophage (M) in control colon stained with $I 2$ monoclonal antibody. The cell surface is strongly stained (the circumferential dark line). The cell has the characteristic appearances of a macrophage; an oval nucleus and little heterochromatin, abundant cytoplasm, numerous mitochondria and vesicles, presence of lysosomes and ruffles, and phagolysosomes. Note surface staining of portion of macrophage in right upper field, unstained plasma cell in left upper field, and eosinophil with intense endogenous peroxidase reaction in granules. There is minimal I2 staining of capillary endothelium in right lower field. $\times 7200$.

Quantitative Counts of I2-Positive Mononuclear Cells in Lamina Propria. In control specimens, 27 of 32 macrophages detected in four small intestinal specimens were 12 positive and 23 of 30 macrophages in four colonic specimens expressed I2 (Table 2). Twenty-five of 44 macrophages detected in four Crohn's ileitis specimens and 43 of 60 macrophages in four ulcerative colitis specimens expressed I2. There was no significant difference in the mean value of macrophage or monocyte expression of 12 between control and IBD. So-called veiled mononuclear cells (dendritic cells), which have irregularly shaped nuclei lined with a rim of chromatin, few ribosomes, few lysosomes, prominent cytoplasmic protrusions, and no endocytic vacuoles $(23,24)$, were not observed in either control or IBD specimens. Birbeck granules (unique structures observed ultrastructurally in Langerhan's cells) $(25,26)$ were not detected. Furthermore, no histological differences in macrophages and monocytes were detected when control and IBD specimens were compared respectively. There were no apparent morphological differences in I2-positive macrophages and monocytes and I2negative macrophages and monocytes.

Of 59 lymphocytes detected in four control small intestinal specimens, none stained for $\mathrm{I} 2$, and only one of 61 lymphocytes detected in four control colonic specimens was I 2 positive. Eleven of 38 lymphocytes detected in four Crohn's ileitis specimens and 24 of 71 lymphocytes detected in four ulcerative colitis specimens were $\mathrm{I} 2$ positive. The 


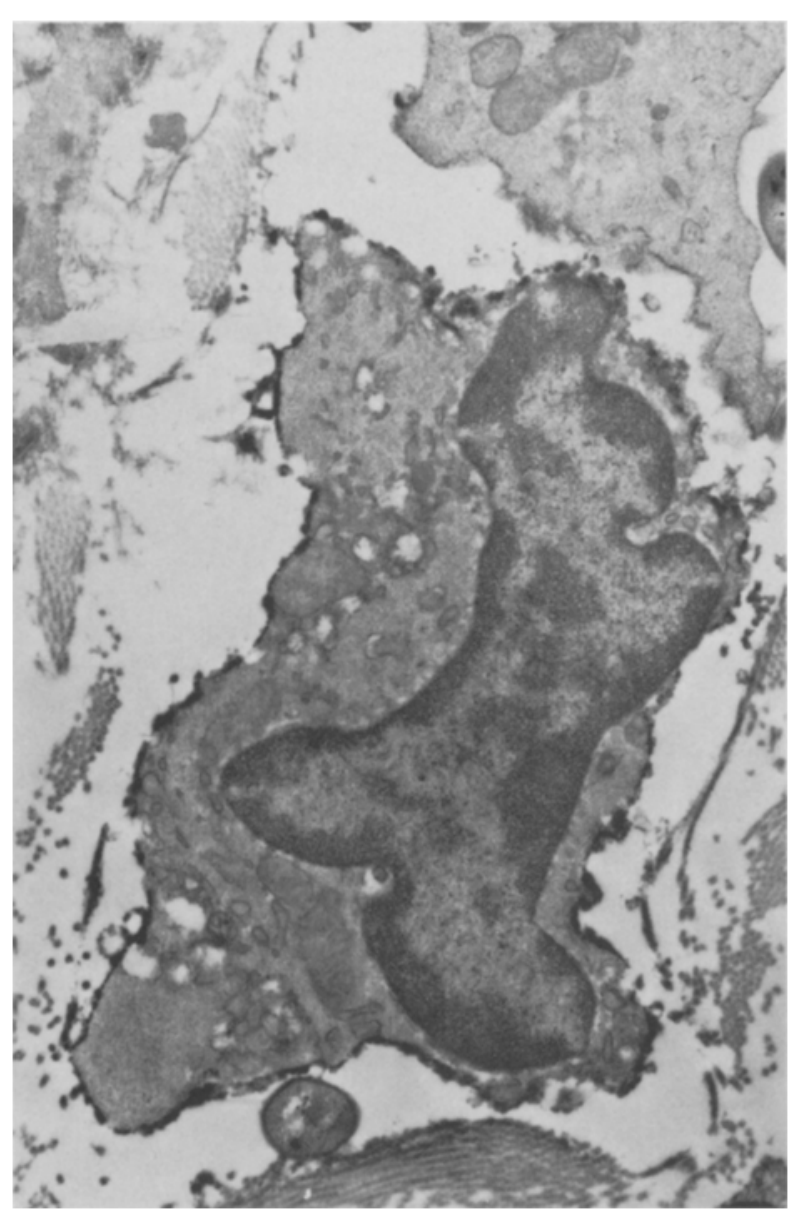

Fig 4. Electron micrograph of a monocyte in control colon stained with I 2 monoclonal antibody. The I2-positive cell shows characteristic appearances of a monocyte; a lobulated nucleus, thick rim of heterochromatin, small amount of cytoplasm, some mitochondria, many vesicles, and absence of phagolysosomes. $\times 14,400$.

number of I2-positive lymphocytes was significantly increased in IBD $(P<0.005$ and $P<0.05)$. There was morphologically no apparent difference between 12-positive lymphocytes and I2-negative lymphocytes. An intimate clumping together of lymphocytes and macrophages-monocytes was sometimes detected: 13 (nine of which contained I2-positive macrophages) in four control small intestinal specimens, nine (seven I2-positive macrophages) in four control colonic specimens, five (three I2-positive macrophages) in four Crohn's ileitis specimens, and 13 (ten 12-positive macrophages) in four ulcerative colitis specimens. Of these $0,0,3$, and 5 , respectively, had associated I2-positive lymphocytes.

\section{DISCUSSION}

We have shown that I2 (HLA-DR) antigen expression is present on surface membranes of both immune and nonimmune cells of control intestine and colon and show that this expression is more prominent in IBD intestine and colon. Control small intestinal epithelium and IBD epithelium expressed I2 while control colonic epithelium did not. I2 expression was more frequent on the lateral and basal surface of enterocytes than on the microvillus surface. M cells were only seen in control ileum and two of the three cells observed expressed 12. Few I2-positive lamina propria lymphocytes (LPL) were found in control, while I2-positive LPL were significantly increased in IBD. Mononuclear cells expressing $\mathrm{I} 2$ in both control and IBD were largely monocytes and macrophages.

The antigen-presenting dendritic cell system in the skin and in the spleen has been extensively studied (24-26). Dendritic cells are easily detected in those tissues. Cells resembling "veiled cells" in terms of moving pattern, strong Ia positivity, and poor acid phosphatase activity have been reported to be present in small numbers in control intestine and in idiopathic inflammatory bowel disease (27). We failed to detect such cells in this study but observed equal proportions of I2-positive monocytes and macrophages in control intestine (60\% of these cells expressed I2), control colon (64\%), Crohn's ileitis (54\%), and ulcerative colitis (67\%). Whether intestinal "dendritic cells" represent a distinct cell type or are variants of monocyte-macrophages has not been determined.

The activated lymphocyte expresses HLA-DR antigen on its cell surface. In the present study, Crohn's ileitis and ulcerative colitis specimens had a significantly increased number of HLA-DR-positive lymphocytes while control small intestinal and control colonic specimens were virtually devoid of HLA-DR-positive lymphocytes. Our data are consistent with previous light microscopic studies in control intestine but inconsistent with previous light microscopic data showing that only a few lamina propria lymphocytes expressed HLA-DR antigen in IBD specimens $(2,3)$. Our observations that LPL express I2 in IBD probably reflects increased certainty of cell identification and increased ease of detection of small amounts of $\mathrm{I} 2$ antigen when using electron microscopic immunoperoxidase techniques.

The lymphocytes identified in this study were not likely to be $\mathrm{I} 2$ positive $\mathrm{B}$ cells but were likely to be 


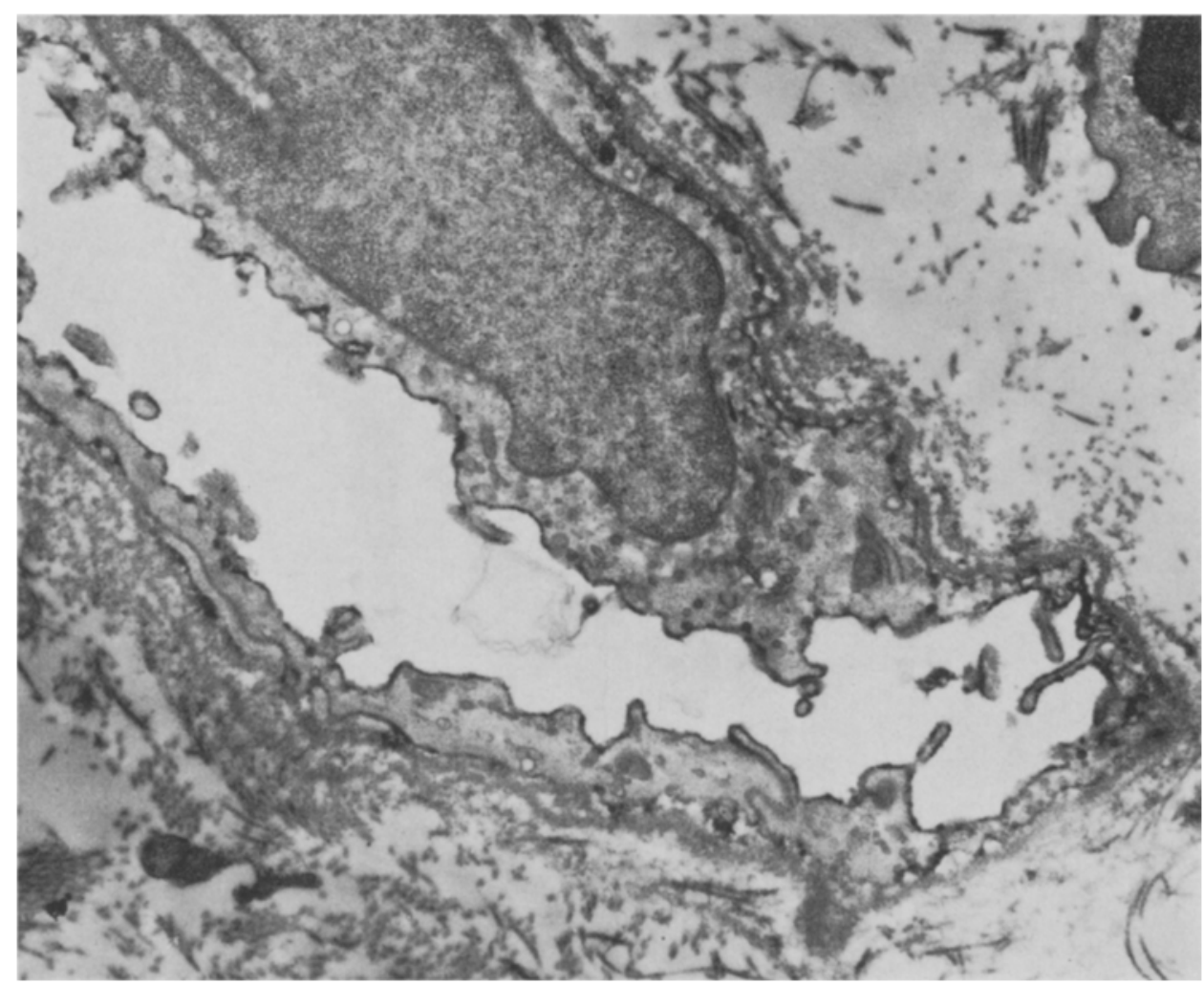

Fig 5. Electron micrograph of capillary endothelium in control colon stained with $\mathrm{I} 2$ monoclonal antibody. The capillary endothelium shows $I 2$ staining on its cell surface, luminal staining being more intense than abluminal staining. $\times 15,600$.

$\mathrm{T}$ cells. We and others have demonstrated that $\mathrm{B}$ lymphocytes, as defined by expression of surface antigen(s) found on B cells (anti-B1 from Coulter Immunology and OK T10 from Ortho Diagnostics), are not found in the intestinal lamina propria $(2,11)$. Plasma cells, cells easily distinguished from $\mathrm{T}$ lymphocytes by their characteristic morphology at electron microscopy, are B-cell derivatives and are profusely present in normal and IBD intestine and colon. Surface immunoglobulin and Ia-like (HLADR) antigens disappear when $B$ cells transform into plasma cells (28). It is possible that a few of the cells identified as HLA-DR-positive lymphocytes were not $T$ cells (the majority of lymphocytes in the lamina propria) but were of B-cell origin. We conclude that IBD tissues have significantly greater numbers of activated $\mathrm{T}$ cells in the lamina propria than do control tissues.

HLA-DR antigen expression by fibroblasts is documented $(2,29)$. Our data show that HLA-DRpositive fibroblasts were rarely detected in control and in IBD specimens and that there seems to be no apparent difference in distribution of HLA-DR- positive fibroblasts between control and IBD specimens. We describe HLA-DR localization to Schwann cells in the gut mucosa for the first time. In a light microscopic study, central and peripheral nervous tissues in normal human were negative for class II antigens, although some fibrous tissue in the dura was positive (18). HLA-DR-positive Schwann cells were much more frequently detected in IBD specimens than in control specimens. The immunologic role of HLA-DR expression in intestinal mucosal Schwann cells, if any, is unknown. Such expression may be important in the immune response of the central nervous system (30).

Capillary endothelia clearly express HLA-DR antigen $(2,11,17,18)$. We confirmed previous studies and observed that the expression of HLADR on the capillary endothelia was easily detected in both control and IBD specimens. No apparent difference in the distribution or intensity of staining of HLA-DR-positive capillary endothelia was detected between control and IBD specimens. In vitro studies show that capillary endothelia may function as antigen-presenting cells $(31,32)$. Because DR 
HIRATA ET AL

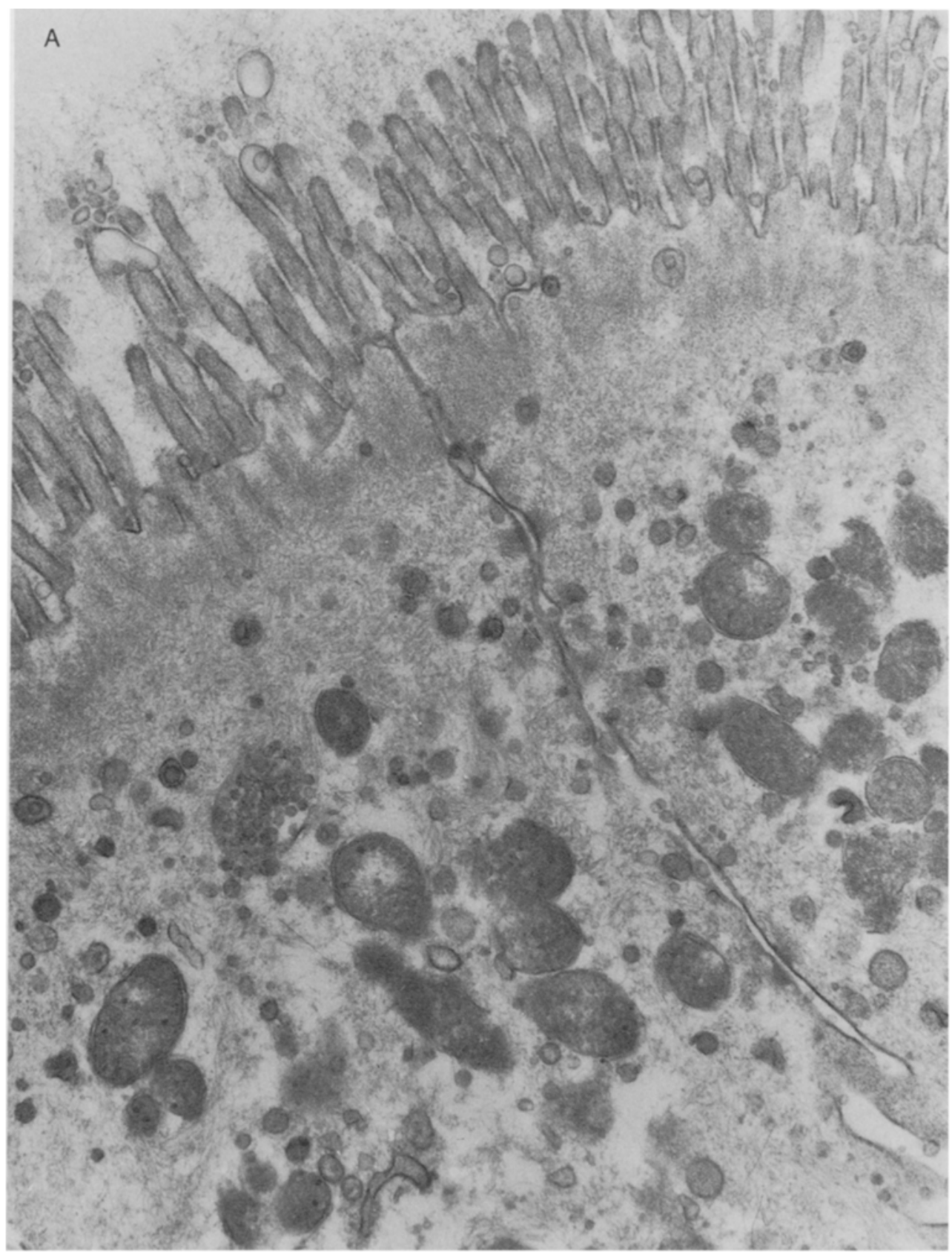

Fig 6. (A) Electron micrograph of control colonic epithelial cells stained with $\mathrm{I} 2$ monoclonal antibody. The epithelium is not stained. $\times 31,900$. (B) Electron micrograph of epithelial cells in ulcerative colitis stained with $\mathbf{2}$ monoclonal antibody. The microvilli and the lateral surface of the epithelium are irregularly stained. Dense staining of apical vesicles (arrow) was also seen in control. $\times 36,700$.

expression by capillary endothelia was similar in both control and IBD, it is difficult to suggest that capillary DR expression in IBD is immunologically important, although this possibility cannot be excluded. We confirm our light microscopic observa- tion that lymphatic endothelium expresses HLADR antigen (2).

It has been documented that the normal small intestinal epithelium and colonic and intestinal IBD epithelium express HLA-DR antigen while normal 


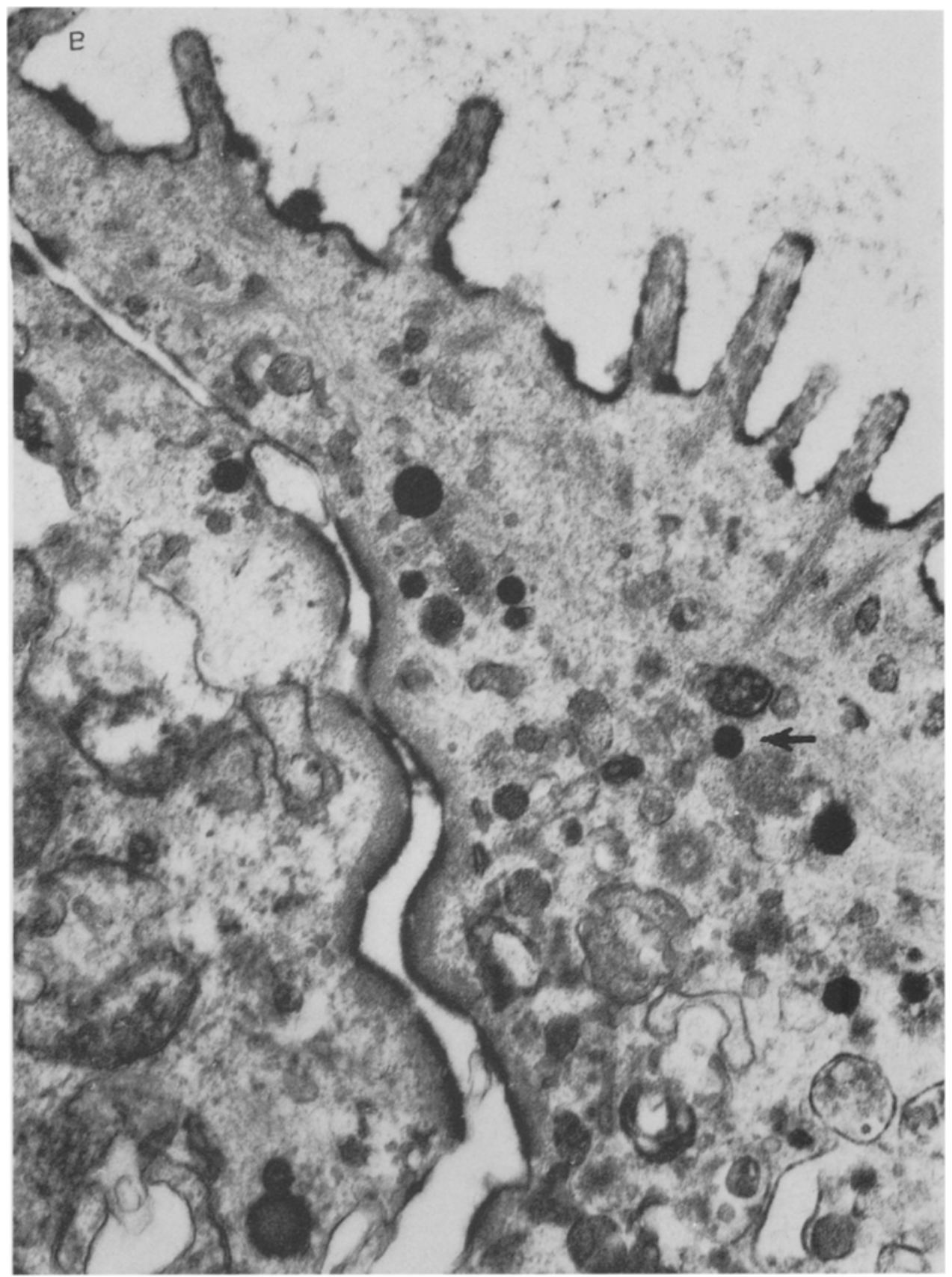

Fig 6. Continued.

colonic epithelium does not $(2,3,11,14,17-19,33)$. We confirm and extend these previous light microscopic studies. The presence of DR expression not only on the apical surface but also on the basolateral surface of epithelial cells clearly shows that epithelial DR is available to cells that are just below the epithelium as well as within the epithelium. The mechanism by which the expression of HLA-DR antigen is induced in colonic epithelium in IBD and is enhanced in intestinal epithelium in Crohn's ileitis is not understood. HLA-DR antigen is induced in the small and large intestinal epithelium and in the epidermis during graft-versus-host disease in the rats $(34,35)$. Furthermore, naturally occurring immunological stimuli, ie, Trichinella spiralis infection of the gut, can induce the expres- 
HIRATA ET AL

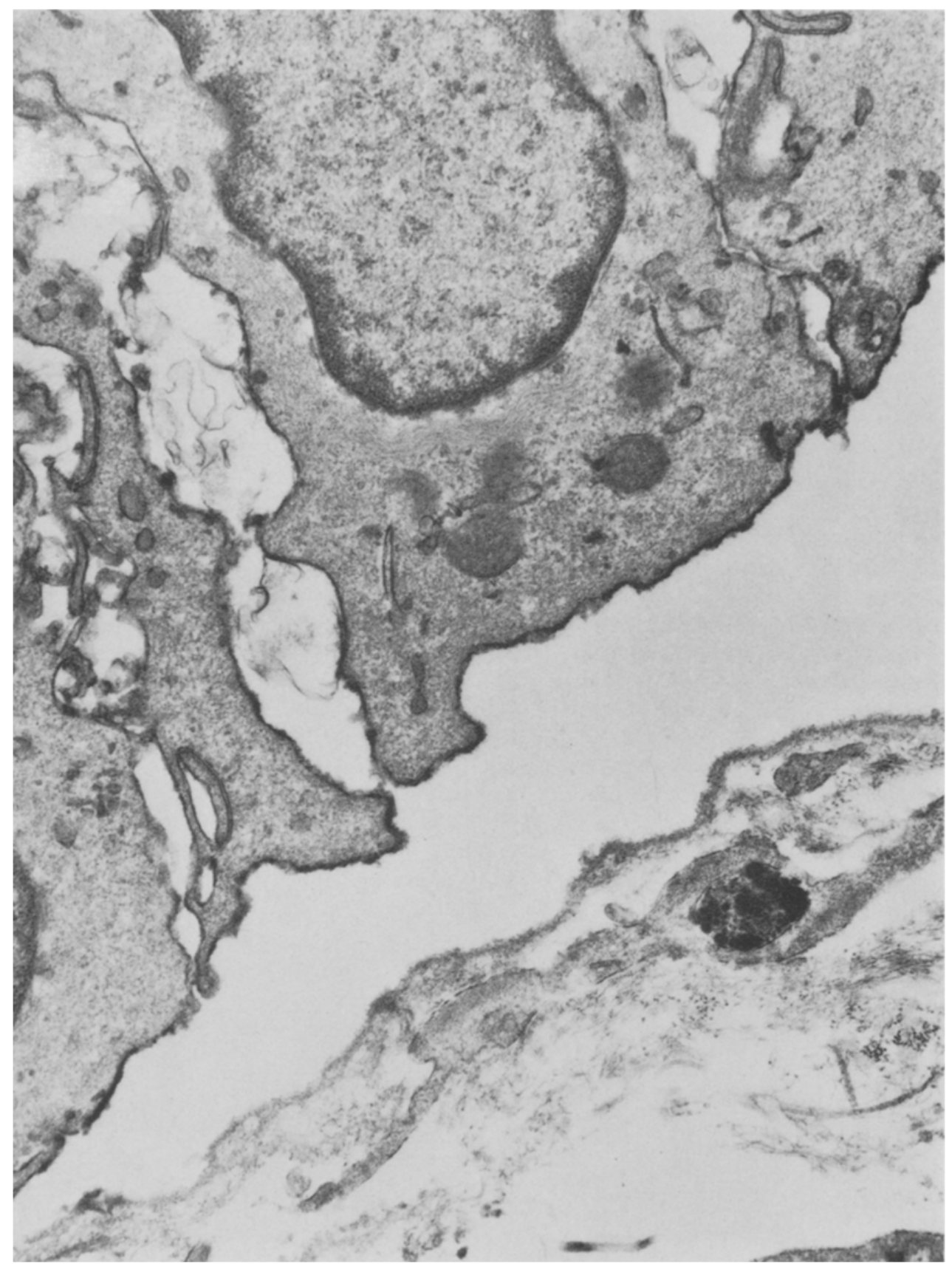

Fig 7. Electron micrograph of epithelial cells in Crohn's ileitis stained with $\mathrm{I} 2$ monoclonal antibody. The basolateral surfaces of the epithelial cells are 12 positive. $\times 25,000$.

sion of Ia antigen in rat gut epithelium (36). Class II antigen expression can be induced on the keratinocytes of rat skin allografts (37), on human follicular thyroid cells cultured with lectins (38), on colorectal cancer cells (18), and on the intestinal epithelium of patients with infectious colitis (19). In relation to these reports, the finding that parental inocula depleted of $\mathrm{T}$ cells failed to induce Ia expression in the gut epithelium of irradiated $F_{1}$ recipients suggested that $T$ cells may be required for Ia induction (36). Mitogen-stimulated IEL have been shown to produce a $\gamma$-interferon-like sub- 


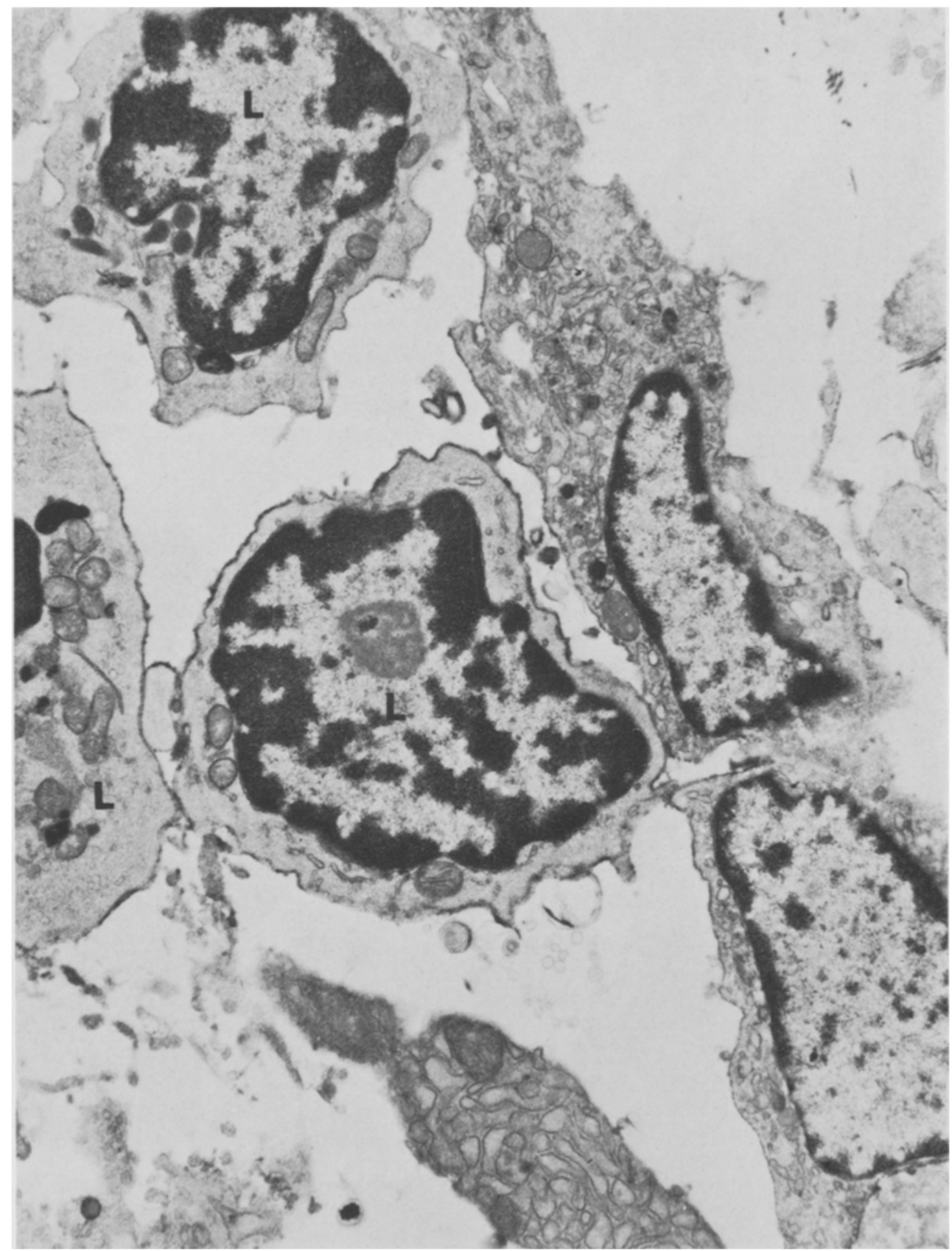

Fig 8. Electron micrograph of lymphocytes (L) in Crohn's ileitis stained with $\mathrm{I} 2$ monoclonal antibody. Two lymphocytes are I2-stained on their cell surface. The lymphocyte in the left upper field is unstained. $\times 11,500$.

stance and to induce Ia expression in an intestinal epithelial cell line (39).

We observed that two of three $M$ cells expressed HLA-DR antigen on the cell surface. It is generally accepted that antigen picked up by the $M$ cell is taken up by underlying mononuclear cells which may subsequently migrate to Peyer's patches and then present antigen to helper $\mathrm{T}$ cells $(40,41)$. However, our observation suggests the possibility that some $M$ cells may process antigen and may directly present the antigen to underlying lymphocytes. 


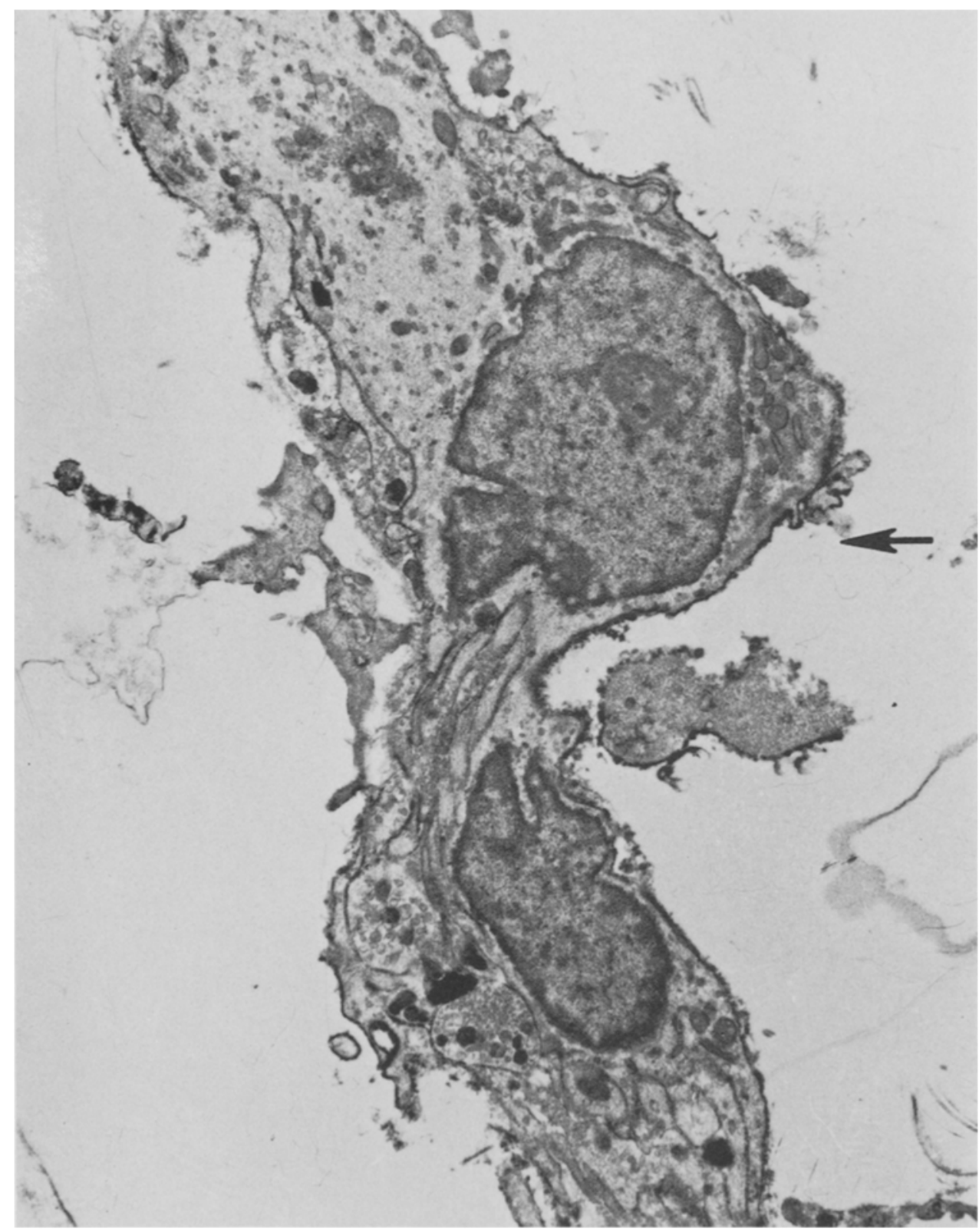

Fig 9. Electron micrograph of a Schwann cell in Crohn's ileitis stained with I2 monoclonal antibody. The Schwann cell is patchily stained (arrow) on its surface. $\times 10,600$.

We rarely detected HLA-DR-positive IEL in control and IBD specimens. It is difficult to detect HLA-DR-positive IEL at light microscopy because of the presence of strong epithelial staining, especially in IBD specimens. Our electron microscopic findings confirm previous light microscopic studies indicating that both control and IBD specimens contain few HLA-DR-positive IEL (2, 3, 11-13). Further studies are necessary to determine whether
HLA-DR expression is involved in the pathogenesis of IBD. It should also be noted that class II MHC antigens may have functions other than antigen presentation, functions including recruitment of $\mathrm{T}$ cells, macrophages, and dendritic cells, and may even provide a signal for homing of $B$ cells to the gut mucosa (18). Our data only provide further evidence of the presence of enhanced cell-mediated immune reactions in inflammatory bowel disease. 


\section{HLA-DR EXPRESSION IN IBD}

Table 2. Distribution of I2 Surface-Staining Macrophages, Monocytes, and Lymphocytes in Lamina Propria of NORMAL INTESTINE AND COLON AND IN IBD*

\begin{tabular}{|c|c|c|c|}
\hline Macrophages & Monocytes & $\begin{array}{c}\text { Macrophage }+ \\
\text { monocytes }\end{array}$ & Lymphocytes \\
\hline \multicolumn{4}{|l|}{ A. Normal intestine } \\
\hline $3 / 4$ & $3 / 11$ & $6 / 15$ & $0 / 11$ \\
\hline $14 / 16$ & $0 / 1$ & $14 / 17$ & $0 / 20$ \\
\hline $4 / 4$ & $0 / 4$ & $4 / 8$ & $0 / 14$ \\
\hline $6 / 8$ & $0 / 1$ & $6 / 9$ & $0 / 14$ \\
\hline$(27 / 32) 84.4 \pm 12.0$ & $(3 / 17) 6.8 \pm 13.7$ & $(30 / 49) 59.8 \pm 18.7$ & $(0 / 59) 0.0 \pm 0.0$ \\
\hline \multicolumn{4}{|l|}{ B. Normal colon } \\
\hline $7 / 7$ & $1 / 9$ & $8 / 16$ & $0 / 8$ \\
\hline $7 / 11$ & $0 / 0$ & $7 / 11$ & $0 / 15$ \\
\hline $3 / 3$ & $2 / 4$ & $5 / 7$ & $1 / 16$ \\
\hline $6 / 9$ & $3 / 4$ & $9 / 13$ & $0 / 22$ \\
\hline$(23 / 30) 82.6 \pm 20.1$ & $(6 / 17) 34.0 \pm 34.7$ & $(29 / 47) 63.6 \pm 9.6$ & $(1 / 61) 1.6 \pm 3.2$ \\
\hline \multicolumn{4}{|l|}{ C. Crohn's ileitis } \\
\hline $8 / 9$ & $0 / 1$ & $8 / 10$ & $1 / 2$ \\
\hline $12 / 15$ & $2 / 2$ & $14 / 17$ & $2 / 15$ \\
\hline $0 / 6$ & $2 / 5$ & $2 / 11$ & $8 / 13$ \\
\hline $5 / 14$ & $1 / 3$ & $6 / 17$ & $0 / 8$ \\
\hline$(25 / 44) 51.2 \pm 41.3$ & $(5 / 11) 43.3 \pm 41.6$ & $(30 / 55) 54.0 \pm 32.2$ & $(11 / 38) 31.1 \pm 29.3$ \\
\hline \multicolumn{4}{|l|}{ D. Ulcerative colitis } \\
\hline $3 / 6$ & $4 / 6$ & $7 / 12$ & $3 / 11$ \\
\hline $10 / 11$ & $13 / 16$ & $23 / 27$ & $18 / 36$ \\
\hline $19 / 26$ & $1 / 4$ & $20 / 30$ & $1 / 15$ \\
\hline $11 / 17$ & $0 / 2$ & $11 / 19$ & $2 / 9$ \\
\hline$(43 / 60) 69.7 \pm 17.1$ & $(18 / 28) 43.3 \pm 37.4$ & $(61 / 88) 67.0 \pm 11.1$ & $(24 / 71) 26.6 \pm 17.9$ \\
\hline A vs C NS & A vs B NS & A vs C NS & A vs $C P<0.005$ \\
\hline B vs D NS & A vs C NS & B vs D NS & $\mathrm{B}$ vs $\mathrm{D} \mathrm{P}<0.05$ \\
\hline & B vs D NS & & \\
\hline
\end{tabular}

*The number of I2-stained cells is listed in the numerator and the total number of cells observed is listed in the denominator. Totals are indicated in parentheses and percentage of I2-stained cells per total number of cells are expressed as mean \pm SD. NS, not significantly different as determined by Student's $t$ test.

\section{ACKNOWLEDGMENTS}

The authors wish to thank Ms. Carolyn White for her valuable assistance in preparing this manuscript.

\section{REFERENCES}

1. Greenwood JH, Austin LL, Dobbins WO III: In vitro characterization of human intestinal intraepithelial lymphocytes. Gastroenterology 85:1023-1035, 1983

2. Hirata I, Berrebi G, Austin LL, Keren DF, Dobbins WO III: Immunohistological characterization of intraepithelial and lamina propria lymphocytes in control ileum and colon and in inflammatory bowel disease. Dig Dis Sci (in press)

3. Selby WS, Janossy G, Bofill M, Jewell DP: Intestinal lymphocyte subpopulations in inflammatory bowel disease: An analysis by immunohistological and cell isolation techniques. Gut 25:32-40, 1984

4. Fiocchi C, Youngman KR, Farmer RG: Immunoregulatory function of human intestinal mucosa lymphoid cells: Evidence for enhanced suppressor cell activity in inflammatory bowel disease. Gut 24:692-701, 1983

5. Goodacre RL, Bienenstock J: Reduced suppressor cell activity in intestinal lymphocytes from patients with Crohn's disease. Gastroenterology 82:653-658, 1982

6. Fiocchi C, Battisto JR, Farmer RG: Studies on isolated gut mucosal lymphocytes in inflammatory bowel disease: Detec- tion of activated $\mathrm{T}$ cells and enhanced proliferation to Staphylococcus aureus and lipopolysaccharides. Dig Dis Sci 26:728-736, 1981

7. Falchuk ZM, Barnhard E, Machado I: Human colonic mononuclear cells: Studies of cytotoxic function. Gut 22:290-294, 1981

8. MacDermott RP, Nash GS, Bertovich MJ, Seiden MV, Bragdon MJ, Beale MG: Alteration of IgM, IgG, and IgA synthesis and secretion by peripheral blood and intestinal mononuclear cells from patients with ulcerative colitis and Crohn's disease. Gastroenterology 81:844-852, 1981

9. MacDermott RP, Franklin GO, Jenkins KM, Kodner IJ, Nash GS, Weinrieb IJ: Human intestinal mononuclear cells. I. Investigations of antibody-dependent lectin-induced, and spontaneous cell-mediated cytotoxic capabilities. Gastroenterology 78:47-56, 1980

10. James SP, Fiocchi C, Graeff AS, Strober W: Immunoregulatory function of lamina propria T cells in Crohn's disease. Gastroenterology 8:1143-1150, 1985

11. Cerf-Bensussan N, Schneeberger EE, Bhan AK: Immunohistologic and immunoelectron microscopic characterization of the mucosal lymphocytes of human small intestine by the use of monoclonal antibodies. J Immunol 130:2615-2622, 1983

12. Selby WS, Janossy G, Bofill M, Jewell DP: Lymphocyte subpopulations in the human small intestine. The findings in 
normal mucosa and in the mucosa of patients with adult celiac disease. Clin Exp Immunol 52:219-228, 1983

13. Selby WS, Janossy G, Jewell DP: Immunohistological characterization of intraepithelial lymphocytes of the human gastrointestinal tract. Gut 22:169-176, 1981

14. Selby WS, Janossy G, Goldstein G, Jewell DP: T lymphocyte subsets in human intestinal mucosa: The distribution and relationship to MHC-derived antigens. Clin Exp Immunol 44:453-458, 1981

15. Schwartz RH: The role of gene products of the major histocompatibility complex in T cell activation and cellular interactions. In Fundamental Immunology. WE Paul (ed). New York, Raven Press, 1984, pp 379-438

16. Shackelford DA, Kaufman JF, Korman AJ, Strominger JL: HLA-DR antigens: Structure, separation of subpopulations, gene cloning and function. Immunol Rev 66:133-187, 1982

17. Scott H, Solheim BG, Brandtzaeg P, Thorsby E: HLA-DRlike antigens in the epithelium of the human small intestine. Scand J Immunol 12:77-82, 1980

18. Daar AS, Fuggle SV, Fabre JW, Ting A, Morris PJ: The detailed distribution of MHC Class II antigens in normal human organs. Transplantation 38:293-298, 1984

19. McDonald GB, Gatter KC, Jewell DP: Immune-associated antigen (HLA-DR) expressions by epithelial cells in inflammatory colitis. Gastroenterology 88:1496, 1985 (abstract)

20. Selby WS, Pulter LW, Hobbs S, Jewell DP, Janossy G: Heterogeneity of HLA-DR-positive histiocytes in human intestinal lamina propria: A combined histochemical and immunohistological analysis. J Clin Pathol 36:379-384, 1983

21. Nadler LM, Stashenko P, Hardy R, Pesnado JM, Yunis EJ, Schlossman SF: Monoclonal antibodies defining serologically distinct HLA-D/DR related Ia-like antigens in man. Hum Immunol 1:77-90, 1981

22. McLean IW, Nakane PK: Periodate-lysine-paraformaldehyde fixative: A new fixative for immunoelectron microscopy. J Histochem Cytochem 22:1077-1083, 1974

23. Van Voorhis WC, Hair LS, Steinman RM, Kaplan G: Human dendritic cells: Enrichment and characterization from peripheral blood. J Exp Med 155:1172-1187, 1982

24. Steinman RM, Nussenzweig MC: Dendritic cells: Features and functions. Immunol Rev 53:127-147, 1980

25. Silberberg-Sinakin I, Gigli I, Baer RL, Thorbecke GJ: Langerhans cells: Role in contact hypersensitivity and relationship to lymphoid dendritic cells and to macrophages. Immunol Rev 53:203-232, 1980

26. Birbeck MS, Breathnach AS, Everall JD: An electron microscope study of basal melanocytes and high-level clear cells (Langerhans cells) in vitiligo. J Invest Dermatol $37: 51-64,1961$
27. Wilders MM, Drexhage HA, Marjankokje, Verspaget HW, Meuwissen SGM: Veiled cells in chronic idiopathic inflammatory bowel disease. Clin Exp Immunol 55:377-387, 1984

28. Nadler LM: Characterization of $\mathrm{B}$ cell antigens. In Leukocyte Typing. A Bernard, L Boumsel, J Dausset, C Milstein, S Schlossman (eds). New York, Springer Verlag, 1984, pp 354-363

29. Shiozawa S, Shiozawa K, Fujita T: Presence of HLA-DR antigen on synovial type A and B cells: An immunoelectron microscopic study in rheumatoid arthritis, osteoarthritis and normal traumatic joints. Immunology 50:587-594, 1983

30. Wong GHW, Bartlett PF, Clark-Lewis I, Battye F, Schrader JW: Inducible expression of $\mathrm{H}-2$ and Ia antigens on brain cells. Nature 310:688-691, 1984

31. Hirschberg H, Braathen LR, Thorsby E: Antigen presentation by vascular endothelial cells and epidermal Langerhans cells: The role of HLA-DR. Immunol Rev 66:57-77, 1982

32. Pober JS, Gimbrone MA, Cotran RS Jr, Reiss CS, Burakoff SJ, Fiers W, Ault KA: Ia expression by vascular endothelium is inducible by activated $\mathrm{T}$ cells and by human $\gamma$ interferon. J Exp Med 157:1339-1353, 1983

33. Selby WS, Janossy G, Mason DY, Jewell DP: Expression of HLA-DR antigens by colonic epithelium in inflammatory bowel disease. Clin Exp Immunol 53:614-618, 1983

34. Mason DW, Dallman M, Barclay AN: Graft-versus-host disease induces expression of Ia antigen in rat epidermal cells and gut epithelium. Nature 293:150-151, 1981

35. Lampert IA, Suitters AJ, Chisholm PM: Expression of Ia antigen on epidermal keratinocytes in graft-versus-host disease. Nature 293:149-150, 1981

36. Barclay AN, Mason DW: Induction of Ia antigen in rat epidermal cells and gut epithelium by immunological stimuli. J Exp Med 156:1665-1676, 1982

37. Barclay AN, Mason DW: Graft rejection and Ia antigens: Paradox resolved. Nature 303:382-383, 1983

38. Pujol-Borrell R, Hanafusa T, Chiovato L, Bottazzo GF: Lectin-induced expression of DR antigen on human cultured follicular thyroid cells. Nature 304:71-73, 1983

39. Cerf-Bensussan N, Quaroni A, Kurnick JT, Bhan AK: Intraepithelial lymphocytes modulate Ia expression by intestinal epithelial cells. J Immunol 132:2244-2252, 1984

40. Owen RL: Sequential uptake of horseradish peroxidase by lymphoid follicle epithelium of Peyer's patches in the normal unobstructed mouse intestine: An ultrastructural study. Gastroenterology 72:440-451, 1977

41. Wolf JL, Bye WA: The membranous epithelial (M) cell and the mucosal immune system. Annu Rev Med 35:95-112, 1984 